\title{
Earthquake response of isolated elevated liquid storage steel tanks
}

\author{
M.K. Shrimali, R.S. Jangid* \\ Department of Civil Engineering, Indian Institute of Technology Bombay, Powai, Mumbai 400 076, India
}

\begin{abstract}
Earthquake response of elevated liquid storage steel tanks isolated by the linear elastomeric bearings is investigated under real earthquake ground motion. Two types of isolated tank models are considered in which the bearings are placed at the base and top of the steel tower structure. The continuous liquid mass of the tank is modelled as lumped masses known as sloshing mass, impulsive mass and rigid mass. The corresponding stiffness constants associated with these lumped masses have been worked out depending upon the properties of the tank wall and liquid mass. The mass of steel tower structure is lumped equally at top and bottom. Since the damping matrix of the isolated tank system is non-classical in nature, the seismic response is obtained by the Newmark's step-by-step method. The response of two types of tanks, namely slender and broad tanks, is obtained and a parametric study is carried out to study the effects of important system parameters on the effectiveness of seismic isolation. The various important parameters considered are the tank aspect ratio, the time period of tower structure, damping and the time period of isolation system. It has been shown that the earthquake response of the isolated tank is significantly reduced. Further, it is also observed that the isolation is more effective for the tank with stiff steel tower structure in comparison to flexible towers. In addition, a simplified analysis is also presented to evaluate the response of the elevated steel tanks using two-degrees-of-freedom model and two single-degree-of-freedom models. It is observed that the proposed analysis predicts the seismic response of elevated steel tanks accurately with significantly less computational efforts.
\end{abstract}

Keywords: Elevated steel tanks; Elastomeric bearings; Isolation; Earthquake; Liquid container; Effectiveness; System parameters 


\section{Introduction}

Even though the elevated liquid storage steel tanks are inherently horizontally flexible, their failure against recent devastating earthquakes has attracted considerable attention of researchers [1]. The tanks are strategically a very important structure as they have vital uses in industries, nuclear power plants and also other activities connected to public life. The tanks are manufactured for a wide range of capacities, from small to very big size. The earthquake motion excites the liquid contained in the tank. A part of the liquid moves independent of the tank wall motion, which is termed, as convective or sloshing while, another part of the liquid, which moves in unison with rigid tank wall, is known as impulsive mass. If the flexibility of the tank wall is considered than the part of the impulsive mass moves independently while remaining accelerates back and forth with tank wall known as rigid mass. The accelerating liquid as sloshing, impulsive and rigid masses, induces substantial hydrodynamic pressures on the tank wall of liquid storage tanks which in turn generates design forces such as base shear and overturning moment. The base shear is important from isolator design view point, while overturning movement produces significant tower deformation and toppling of the same leads to failure of the tank. The failure of the liquid storage steel tanks is mainly due to buckling of tank wall, toppling of the tower structure, failure of piping system and uplift of the anchorage system.

The seismic behaviour of the elevated liquid storage tank is highly complex due to liquid-structure-interaction leading to a tedious design procedure from earthquakeresistant design point of view. A few studies to model the ground supported liquid storage and their dynamic response were conducted to understand their behaviour. Housner [2] developed theoretical lumped mass model of ground supported liquid storage tank with two-degrees-of-freedom, which are associated with sloshing mass and impulsive mass, to investigate the seismic response. It is observed that the liquid pressure generated due to earthquake ground motion is very important for seismic design of the tanks. Rosenblueth and Newmark [3] modified the expressions of Housner [2] to estimate the sloshing and impulsive mass to evaluate the seismic design forces of liquid storage tanks. A three-degrees-of-freedom model of ground supported liquid storage tank has been developed by Haroun [4] and has derived the design charts to estimate sloshing, impulsive and rigid masses with assumptions that the liquid contained in the tank is incompressible and has irrotational flow. Hamdan [5] investigated the seismic response of cylindrical steel ground supported tanks. The results of theoretical model based upon finite element technique compared with response obtained by various codified recommendations emphasised that there is a need to investigate the response of the tanks accounting for the contribution of each component of fluid motion.

In order to protect the structure against the possible hazard of earthquake, it is strengthened conventionally, which may attract higher earthquake forces. The other alternative technique is isolation. Earthquake isolation is achieved by implanting certain isolation devices to decouple from ground to reduce peak response of the structure. Since the forces transmitted to the superstructure have been largely 
reduced, the superstructure can usually be expected to be linearly elastic, even under the excitation of severe earthquakes. The base isolation techniques have been developed and successfully implemented in buildings and bridges [6-8]. For ground supported isolated liquid storage tanks, the dynamic responses were investigated and it was found that the base isolation is also effective in reducing the earthquake response. Chalhoub and Kelly [9] observed that the sloshing response increases slightly, while the total hydrodynamic pressure decreases substantially due to base isolation of the tanks. Kim and Lee [10] experimentally investigated the seismic performance of liquid storage tanks isolated by laminated rubber bearings under unidirectional excitation and showned that the isolation is effective in reducing the dynamic response. Malhotra [11-12] studied the seismic response of isolated liquid storage tanks, under uni-directional ground motion, in which the tank wall was isolated from the base plate by horizontal flexible rubber bearings. The study indicated that the isolation is quite effective in reducing the axial stresses of cylindrical shell. Recently, Shrimali and Jangid [13-14] investigated the response of slender and broad liquid storage tanks under bi-directional earthquake motion to study the interaction effects of restoring forces of the isolators, although the above studies confirm that the seismic isolation is effective in reducing the earthquake response of the ground supported tanks. However, very limited studies were conducted to investigate the effects of seismic isolation on the response of elevated liquid storage tanks. Bleiman and Kim [15] proposed isolation as an effective method for rehabilitation of the elevated liquid storage tanks. Shenton and Hampton [16] investigated the influence of liquid height on seismic response of the isolated elevated tank. It is to be noted that the above studies confirm that the isolation is also effective for elevated liquid storage tank, but there is a need to further study the response of elevated isolated tank under different system parameters which will be helpful in understanding the dynamic behaviour for optimum design of isolation systems.

Herein, the earthquake response of elevated liquid storage tanks isolated by the linear elastomeric bearings is investigated using recorded earthquake ground motions. The specific objectives of the study are: (i) to investigate the seismic response of the isolated tanks considering the influence of various tank, tower and isolation parameters and compare with corresponding response of non-isolated tank to identify the effectiveness of isolation system, (ii) to evaluate for wide range of practical liquid storage tanks, the contribution of various components of base shear to total base shear and influence of isolation on sloshing displacement and deformation of tower structure (i.e. tower drift), (iii) to study the comparative performance of base isolated tanks when isolation bearings are paced at top and bottom of the supporting tower structure and (iv) to investigate the response of the isolated elevated liquid storage steel tanks by the proposed approximate models to minimize the computational efforts.

\section{Structural model of liquid storage tank}

A structural model of liquid storage cylindrical tank mounted on steel tower structure, which is fixed to the ground, is shown in Fig. 1(a). The supporting system to 
(a)

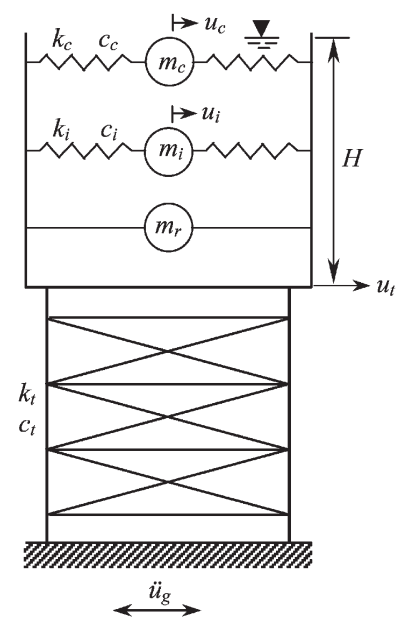

(b)

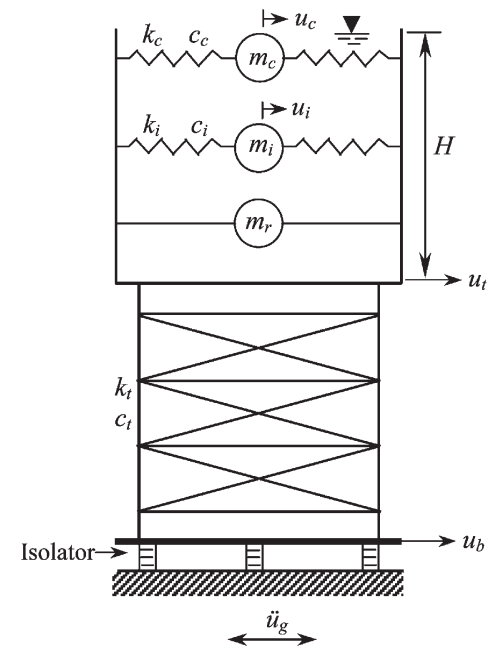

(c)

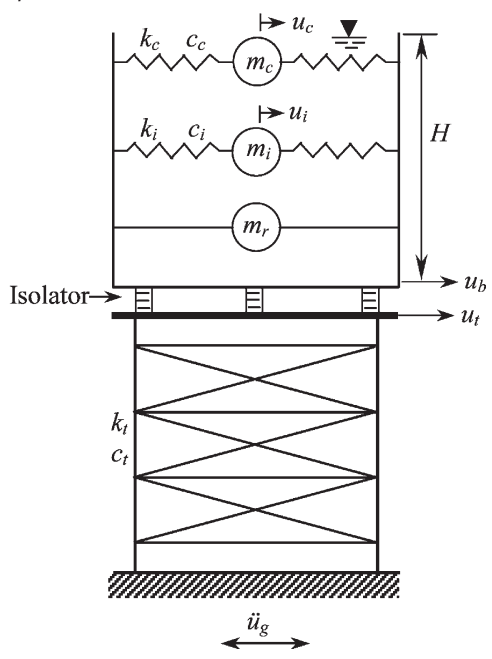

Fig. 1. Structural model of elevated liquid storage steel tank: (a) non-isolated, (b) with isolation at bottom (isolated model-I) and with isolation at top (isolated model-II).

the liquid container considered is columnar type (i.e. tower structure). The continuous liquid mass is lumped as sloshing, impulsive and rigid masses and referred to as $m_{\mathrm{c}}$, $m_{\mathrm{i}}$ and $m_{\mathrm{r}}$, respectively. The sloshing and impulsive masses are connected to the tank wall by corresponding equivalent springs having stiffness constants $k_{\mathrm{c}}$ and $k_{\mathrm{i}}$, respectively. The damping constants of the sloshing and impulsive masses are $c_{\mathrm{c}}$ and $c_{\mathrm{i}}$, respectively. The tank has three-degrees-of-freedom under uni-directional excitation as $u_{\mathrm{c}}, u_{\mathrm{i}}$ and $\mathrm{u}_{\mathrm{t}}$ which denote the absolute displacements of sloshing mass, impulsive mass and tower drift, respectively. The elevated tank is isolated by two 
techniques, namely, by placing the bearings between the base of tower structure and foundation (referred as isolated model-I as shown in Fig. 1(b)) and by placing the bearings between bottom of the liquid container and top of the tower structure (referred as isolated model-II as shown in Fig. 1(c).

Due to the introduction of the isolation system, the tank has one additional degreeof-freedom which corresponds to the deformation in the isolation system and denoted by $u_{\mathrm{b}}$. The isolation system considered for the present study is laminated rubber bearings with alternate layers of steel and rubber. The presence of steel plates in the isolation bearings makes it rigid in the vertical direction. The force-deformation behaviour of the bearings is considered to be linear with viscous damping. The influence of uplift and rocking are not considered in the response evaluation of the isolated tanks under earthquake excitation. The self-weight of steel tower structure and base mass (i.e. mass of base plate) is assumed as 10 and 5\% of the liquid mass, respectively [15].

The geometrical parameters of the tanks considered are liquid height $H$, radius, $R$ and average thickness of tank wall, $t_{\mathrm{h}}$. The non-dimensional parameters $Y_{\mathrm{c}}, Y_{\mathrm{i}}, Y_{\mathrm{r}}$ and $P$ are functions of the aspect ratio of the tank, $S$, which are expressed in Ref. [4] by

$$
\left\{\begin{array}{l}
Y_{\mathrm{c}} \\
Y_{\mathrm{i}} \\
Y_{\mathrm{r}} \\
P
\end{array}\right\}=\left[\begin{array}{lllll}
1.01327 & -0.8757 & 0.35708 & 0.06692 & 0.00439 \\
-0.15467 & 1.21716 & -0.62839 & 0.14434 & -0.0125 \\
-0.01599 & 0.86356 & -0.30941 & 0.04083 & 0 \\
0.037085 & 0.084302 & -0.05088 & 0.012523 & -0.0012
\end{array}\right]\left\{\begin{array}{l}
1 \\
S \\
S^{2} \\
S^{3} \\
S^{4}
\end{array}\right\}
$$

where $S=H / R$ is the aspect ratio (i.e. ratio of the liquid height to radius of the tank) and $Y_{\mathrm{c}}, Y_{\mathrm{i}}$, and $Y_{\mathrm{r}}$ are the mass ratios defined as

$$
\begin{aligned}
Y_{\mathrm{c}} & =\frac{m_{\mathrm{c}}}{m} \\
Y_{\mathrm{i}} & =\frac{m_{\mathrm{i}}}{m} \\
Y_{\mathrm{r}} & =\frac{m_{\mathrm{r}}}{m} \\
m & =\pi R^{2} H \rho_{\mathrm{w}}
\end{aligned}
$$

where $\rho_{\mathrm{w}}$ is the mass density of liquid.

The natural frequencies of sloshing mass, $\omega_{\mathrm{c}}$ and impulsive mass, $\omega_{\mathrm{i}}$ are given by the following expression [4] as

$$
\omega_{\mathrm{i}}=\frac{P}{H} \sqrt{\frac{E}{\rho_{\mathrm{s}}}}
$$




$$
\omega_{\mathrm{c}}=\sqrt{1.84\left(\frac{g}{R}\right) \tanh (1.84 S)}
$$

where $E$ and $\rho_{\mathrm{s}}$ are the modulus of elasticity and density of tank wall, respectively; $g$ is the acceleration due to gravity.

The equivalent stiffness and damping of the sloshing and impulsive masses are expressed as

$$
\begin{aligned}
& k_{\mathrm{c}}=m_{\mathrm{c}} \omega_{\mathrm{c}}^{2} \\
& k_{\mathrm{i}}=m_{\mathrm{i}} \omega_{\mathrm{i}}^{2} \\
& c_{\mathrm{c}}=2 \xi_{\mathrm{c}} m_{\mathrm{c}} \omega_{\mathrm{c}} \\
& c_{\mathrm{i}}=2 \xi_{\mathrm{i}} m_{\mathrm{i}} \omega_{\mathrm{i}}
\end{aligned}
$$

where $\xi_{\mathrm{c}}$ and $\xi_{\mathrm{i}}$ are damping ratio of sloshing mass and impulsive mass, respectively.

\section{Governing equations of motion}

The equations of motion of elevated liquid storage tank subjected to uni-directional earthquake ground motion are expressed in the matrix form as

$$
[m]\{\ddot{x}\}+[c]\{\dot{x}\}+[k]\{x\}=-[m]\{r\} \ddot{u}_{\mathrm{g}}
$$

where $\{x\}$ is the displacement vector; $[m],[c]$ and $[k]$ are the mass, damping and stiffness matrix of the system, respectively; $\{r\}$ is the influence coefficient vector; and $\ddot{u}_{\mathrm{g}}$ is the earthquake acceleration.

The displacement vector for non-isolated tank is given by $\{x\}=\left\{x_{\mathrm{c}}, x_{\mathrm{i}}, x_{\mathrm{t}}\right\}^{\mathrm{T}} ; x_{c}=$ $u_{c}-u_{t}$ is the relative displacement of the sloshing mass, $x_{i}=u_{i}-u_{t}$ is the displacement of the impulsive mass; $x_{s}=u_{t}-u_{g}$ is the tower displacement relative to ground (i.e. tower drift). The matrices $[m],[c],[k]$ and the vector $\{r\}$ for non-isolated tank are expressed as

$$
\begin{aligned}
& {[m]=\left[\begin{array}{lll}
m_{\mathrm{c}} & 0 & m_{\mathrm{c}} \\
0 & m_{\mathrm{i}} & m_{\mathrm{i}} \\
m_{\mathrm{c}} & m_{\mathrm{i}} & M+m_{\mathrm{b}}
\end{array}\right]} \\
& {[c]=\operatorname{diag}\left[c_{\mathrm{c}}, c_{\mathrm{i}}, c_{\mathrm{t}}\right]} \\
& {[k]=\operatorname{diag}\left[k_{\mathrm{c}}, k_{\mathrm{i}}, k_{\mathrm{t}}\right]} \\
& \{r\}=\{0,0,1\}^{\mathrm{T}}
\end{aligned}
$$

where $M=m_{c}+m_{i}+m_{r}$ is the effective mass of the tank and $m_{\mathrm{b}}$ is equal to $0.05 m$.

The stiffness, $k_{\mathrm{t}}$ and damping, $c_{\mathrm{t}}$ of the tower structure are based on the assumption of equivalent single-degree-of-freedom system which are defined as 


$$
\begin{aligned}
& k_{\mathrm{t}}=\left(\frac{2 \pi}{T_{\mathrm{t}}}\right)^{2}(M+0.05 m) \\
& c_{\mathrm{t}}=2 \xi_{\mathrm{t}}(M+0.05 m) \omega_{\mathrm{t}}
\end{aligned}
$$

where $T_{\mathrm{t}}$ and $\xi_{\mathrm{t}}$ are time period and damping ratio of the tower structure.

The displacement vector for the isolated model-I is expressed as $\{x\}=$ $\left\{x_{\mathrm{c}}, x_{\mathrm{i}}, x_{\mathrm{t}}, x_{\mathrm{b}}\right\}^{\mathrm{T}} ; x_{c}=u_{c}-u_{t}$ is the relative displacement of the sloshing mass, $x_{i}=$ $u_{i}-u_{t}$ is the relative displacement of the impulsive mass; $x_{s}=u_{t}-u_{b}$ is the tower displacement (i.e. tower drift) and $x_{b}=u_{b}-u_{g}$ is the relative bearing displacement. The matrices $[m],[c],[k]$ and the vector $\{r\}$ are expressed as

$$
\begin{aligned}
& {[m]=\left[\begin{array}{llll}
m_{\mathrm{c}} & 0 & m_{\mathrm{c}} & m_{\mathrm{c}} \\
0 & m_{\mathrm{i}} & m_{\mathrm{i}} & m_{\mathrm{i}} \\
m_{\mathrm{c}} & m_{\mathrm{i}} & M+m_{\mathrm{b}} & M+m_{\mathrm{b}} \\
m_{\mathrm{c}} & m_{\mathrm{i}} & M+m_{\mathrm{b}} & M+3 m_{\mathrm{b}}
\end{array}\right]} \\
& {[c]=\operatorname{diag}\left[c_{\mathrm{c}}, c_{\mathrm{i}}, c_{\mathrm{s}}, c_{\mathrm{b}}\right]} \\
& {[k]=\operatorname{diag}\left[k_{\mathrm{c}}, k_{\mathrm{i}}, k_{s}, k_{\mathrm{b}}\right]} \\
& \{r\}=\{0,0,0,1\}^{\mathrm{T}}
\end{aligned}
$$

The stiffness, $k_{\mathrm{b}}$ and damping, $c_{\mathrm{b}}$ of the isolation are defined as

$$
\begin{aligned}
& k_{\mathrm{b}}=\left(\frac{2 \pi}{T_{\mathrm{b}}}\right)^{2}(M+0.15 m) \\
& c_{\mathrm{b}}=2 \xi_{\mathrm{b}}(M+0.15 m) \omega_{\mathrm{b}}
\end{aligned}
$$

where $T_{\mathrm{b}}$ and $\xi_{\mathrm{b}}$ are time period and damping ratio of isolation system; and $\omega_{\mathrm{b}}$ is the isolation frequency. The tower stiffness and damping are computed using Eqs. (17) and (18), respectively.

Similarly, the displacement vector for isolated model-II is expressed as $\{x\}=$ $\left\{x_{\mathrm{c}}, x_{\mathrm{i}}, x_{\mathrm{b}}, x_{\mathrm{t}}\right\}^{\mathrm{T}} ; x_{c}=u_{c}-u_{b}$ is the relative displacement of the sloshing mass, $x_{i}=$ $u_{i}-u_{b}$ is the displacement of the impulsive mass; $x_{b}=u_{b}-u_{t}$ is the relative bearing displacement; $x_{s}=u_{t}-u_{g}$ is the relative tower displacement. The matrices $[m],[c]$, $[k]$ and the vector $\{r\}$ are expressed as

$$
\begin{aligned}
& {[m]=\left[\begin{array}{llll}
m_{\mathrm{c}} & 0 & m_{\mathrm{c}} & m_{\mathrm{c}} \\
0 & m_{\mathrm{i}} & m_{\mathrm{i}} & m_{\mathrm{i}} \\
m_{\mathrm{c}} & m_{\mathrm{i}} & M & M \\
m_{\mathrm{c}} & m_{\mathrm{i}} & M & M+2 m_{\mathrm{b}}
\end{array}\right]} \\
& {[c]=\operatorname{diag}\left[c_{\mathrm{c}}, c_{\mathrm{i}}, c_{\mathrm{b}}, c_{\mathrm{t}}\right]}
\end{aligned}
$$




$$
\begin{aligned}
& {[k]=\operatorname{diag}\left[k_{\mathrm{c}}, k_{\mathrm{i}}, k_{\mathrm{b}}, k_{\mathrm{t}}\right]} \\
& \{r\}=\{0,0,0,1\}^{\mathrm{T}}
\end{aligned}
$$

The stiffness and damping of the isolation system and tower structure are expressed as

$$
\begin{aligned}
k_{\mathrm{t}} & =\left(\frac{2 \pi}{T_{\mathrm{t}}}\right)^{2}(M+0.1 m) \\
k_{\mathrm{b}} & =\left(\frac{2 \pi}{T_{\mathrm{b}}}\right)^{2} M \\
c_{\mathrm{t}} & =2 \xi_{\mathrm{t}}(M+0.1 m) \omega_{\mathrm{t}} \\
c_{\mathrm{b}} & =2 \xi_{\mathrm{b}} M \omega_{\mathrm{b}}
\end{aligned}
$$

Since the damping level in the isolator, supporting steel tower and vibrating liquid is very different, the equations of motion of the isolated elevated liquid storage tank cannot be solved using classical modal superposition technique. Alternatively, the equations of motion are solved in the incremental form using Newmark's step-bystep method assuming linear variation of acceleration over small time interval, $\Delta t$.

After obtaining the acceleration vector, the base shear is computed, which is directly proportional to earthquake forces transmitted to the tank is expressed as

$$
F_{\mathrm{b}}=m_{\mathrm{c}} \ddot{u}_{\mathrm{c}}+m_{\mathrm{i}} \ddot{u}_{\mathrm{i}}+\left(m_{\mathrm{r}}+0.05 m\right) \ddot{u}_{\mathrm{t}}(\text { for non }- \text { isolated model })
$$

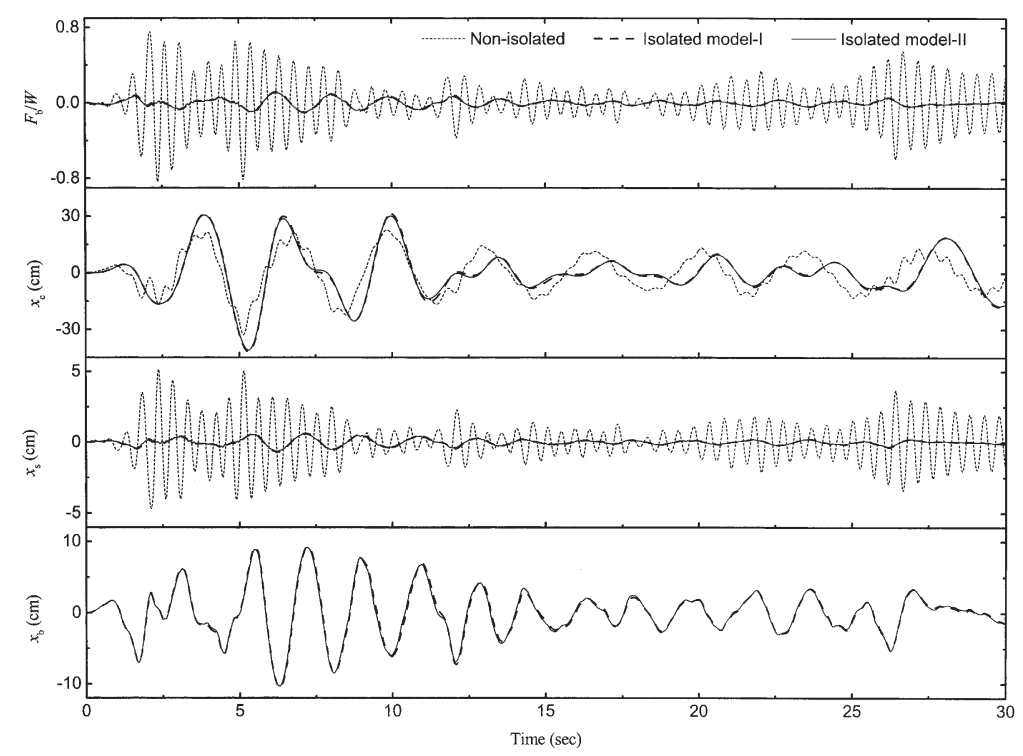

Fig. 2. Time variation of slender tank response under Imperial Valley, 1940 earthquake motion $\left(T_{b}=\right.$ $2 \mathrm{~s}, \xi_{b}=0.1$ and $T_{t}=0.5 \mathrm{~s}$ ). 


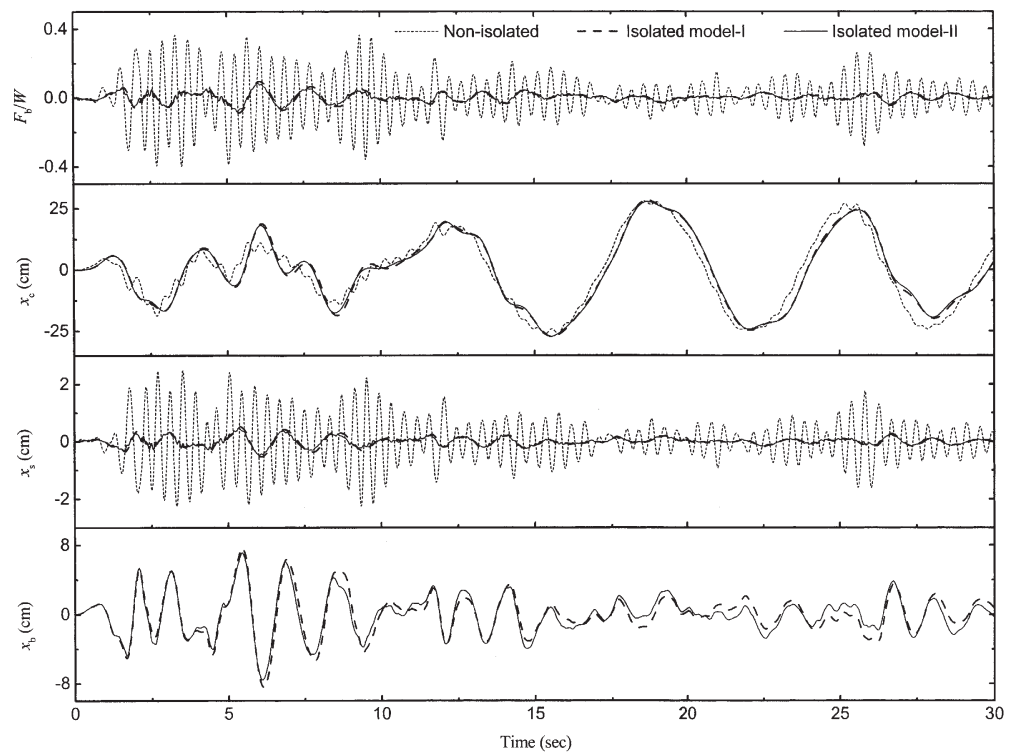

Fig. 3. Time variation of broad tank response under Imperial Valley, 1940 earthquake motion $\left(T_{b}=2\right.$ $\mathrm{s}, \xi_{b}=0.1$ and $T_{t}=0.5 \mathrm{~s}$ ).

$$
\begin{aligned}
& F_{\mathrm{b}}=m_{\mathrm{c}} \ddot{u}_{\mathrm{c}}+m_{\mathrm{i}} \ddot{u}_{\mathrm{i}}+\left(m_{\mathrm{r}}+0.05\right) \ddot{u}_{\mathrm{t}}+2 m_{\mathrm{b}} \ddot{u}_{\mathrm{b}} \quad(\text { for isolated model }-\mathrm{I}) \\
& F_{\mathrm{b}}=m_{\mathrm{c}} \ddot{u}_{\mathrm{c}}+m_{\mathrm{i}} \ddot{u}_{\mathrm{i}}+m_{\mathrm{r}} \ddot{u}_{\mathrm{b}}+2 m_{\mathrm{b}} \ddot{u}_{\mathrm{t}}(\text { for isolated model }-\mathrm{II})
\end{aligned}
$$

\section{Numerical study}

Earthquake response of elevated isolated liquid storage steel tanks, namely slender and broad tanks, is investigated. The properties of these tanks are: (i) the aspect ratio, $S$ for slender and broad tanks is 1.85 and 0.6 , respectively, (ii) the height, $H$, of water filled in the slender and broad tanks is $10 \mathrm{~m}$ and (iii) the ratio of tank wall thickness to its radius is taken to be 0.004 for both tanks. The natural frequencies of sloshing and impulsive mass are 0.148 and $5.757 \mathrm{~Hz}$ (for broad tank) and 0.291 and $6.738 \mathrm{~Hz}$ (for slender tank). The tank wall is considered of steel with modulus of elasticity, $E=200 \mathrm{MPa}$ and mass density, $\rho_{s}=7900 \mathrm{~kg} / \mathrm{m}^{3}$. The earthquake response of isolated tank is investigated for two tank models (i.e. models I and II). The response quantities of interest are base shear (measured at bottom of the foundation level of the structure), $F_{b} / W(W=M g)$, sloshing displacement $\left(x_{\mathrm{c}}\right)$, drift of tower structure $\left(x_{\mathrm{s}}\right)$ and displacement at top of the interface of isolation bearings, $x_{\mathrm{b}}$. For the present study, the components S00E, NO0E and NO0E of Imperial Valley (1940), Loma Prieta (1989) and Kobe (1995) earthquake ground motions, respectively, are used to investigate the response of the tank. The peak ground accelerations of the Imperial Valley, Loma Prieta and Kobe earthquake records are 0.348, 0.570 and $0.834 \mathrm{~g}$, respectively. 


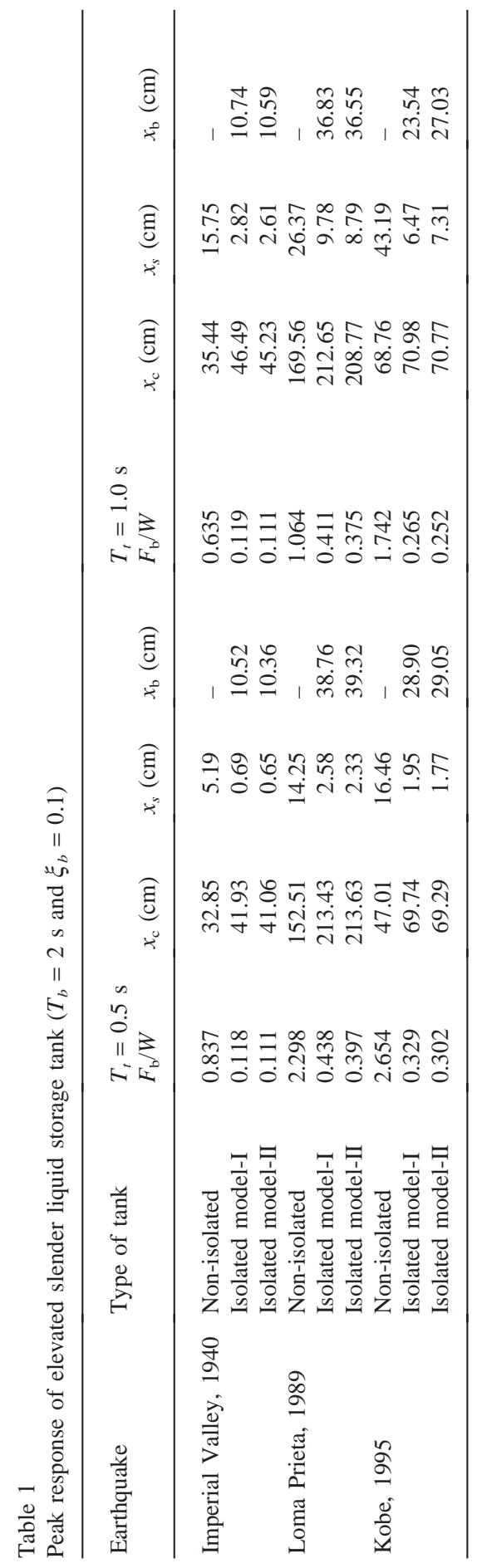




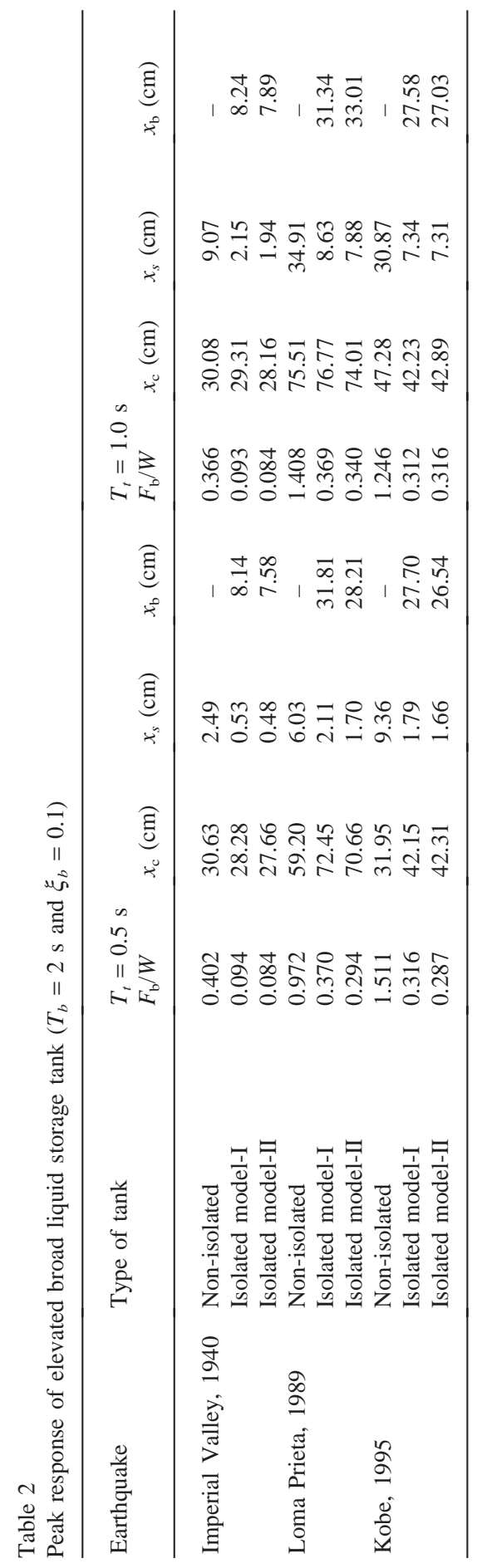



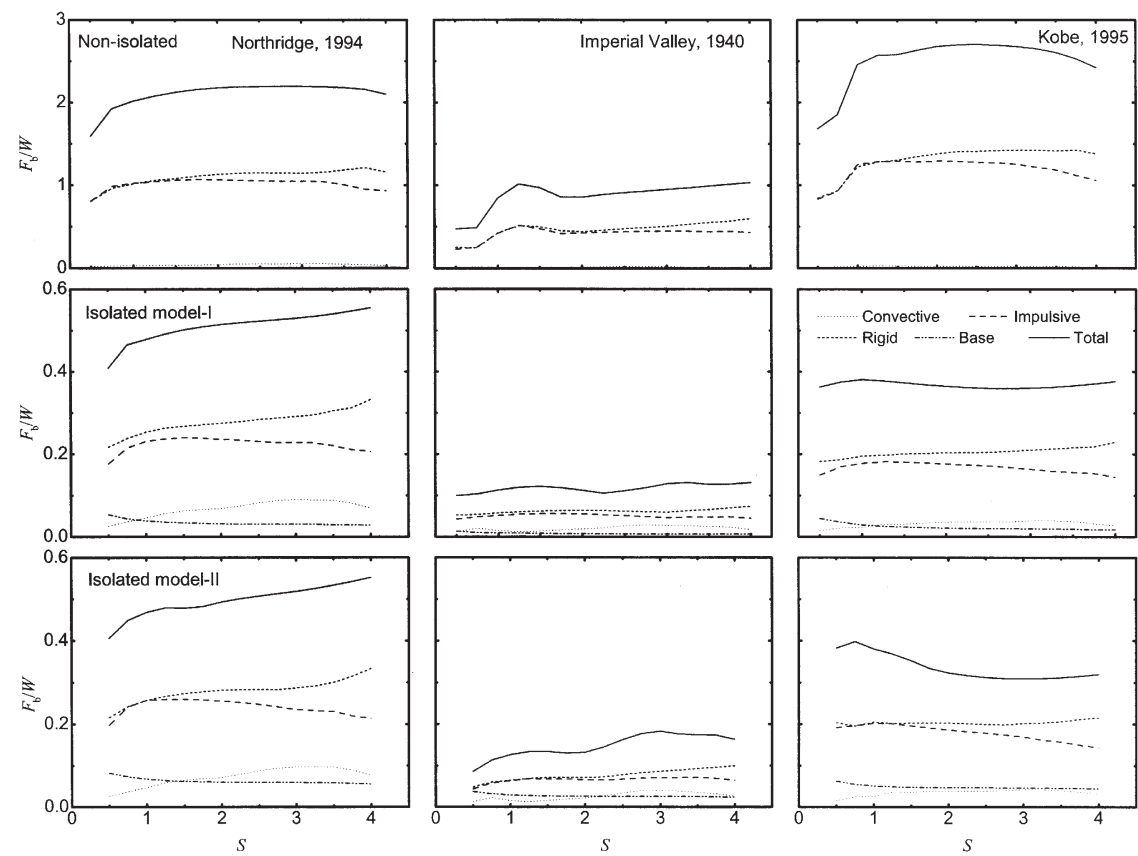

Fig. 4. Variation of base shear components of elevated tank against aspect ratio $\left(T_{b}=2 \mathrm{~s}, \xi_{b}=0.1\right.$ and $\left.T_{t}=0.5 \mathrm{~s}\right)$.

Figs. 2 and 3 show the time variation of response of the elevated slender and broad tanks, respectively, under Imperial Valley, 1940 earthquake motion. The model parameters considered are $T_{b}=2 \mathrm{~s}, \xi_{b}=0.1$ and $T_{t}=0.5 \mathrm{~s}$. The figures indicate that the variation of the response of the two isolated tank models (i.e. isolated models I and II) is identical and closely matched. The base shear and tower drift of the isolated tanks are significantly reduced in comparison to those of corresponding nonisolated tanks. The peak bearing displacements in slender tank for isolated models I and II are 10.52 and $10.36 \mathrm{~cm}$, while for broad tank, the corresponding displacements are 8.14 and $7.58 \mathrm{~cm}$. This indicates that bearing displacement is comparatively less in broad tank. It is also observed from Figs. 2 and 3 that the bearing displacement produced in the isolated model-II is marginally less in comparison to that of isolated model-I. Further, the sloshing displacement in slender tank due to isolation is increased considerably, while in broad tank, there is no significant change.

Tables 1 and 2 show the comparative study of the peak response of isolated elevated slender and broad tanks against corresponding non-isolated tanks for two different values of period of tower structure (i.e. $T_{t}=0.5$ and $1 \mathrm{~s}$ ), respectively. The isolation parameters considered are $T_{b}=2 \mathrm{~s}, \xi_{b}=0.1$. The tables indicate that for slender tank the percentage reduction in base shear due to isolation, at $T_{t}=0.5 \mathrm{~s}$ for isolated model-I is 85.90, 80.94 and 87.60 under Imperial Valley, Loma Prieta and Kobe earthquakes, respectively, while the corresponding reduction at $T_{t}=1 \mathrm{~s}$ is $81.26,61.37$ and 84.78. Similarly, for broad tank, the corresponding reduction at 
$T_{t}=0.5$ and $1 \mathrm{~s}$ is $(76.62,61.93$ and 79.09$)$ and $(74.59,73.79$ and 74.96), respectively for different earthquakes. For isolated model-II, the percentage reduction in base shear for slender tank at $T_{t}=0.5$ and $1 \mathrm{~s}$ is $(86.74,82.72$ and 88.62) and (82.52, 64.76 and 85.53), respectively. Similarly, for broad tank, the corresponding reduction is $(79.10,69.76$ and 81.01$)$ and $(77.05,75.85$ and 74.64$)$. The above results indicate that due to isolation of the tanks, base shear is reduced significantly. The reduction in base shear is comparatively more in slender tank. In addition, it is also observed that the reduction in base shear for isolated model-II is slightly more in comparison to isolated model-I. The comparative results indicate that reduction in the base shear is slightly more in tank with stiff tower structure in comparison to that in flexible towers. The percentage reduction in tower displacement for slender tank (i.e. tower drift) in isolated model-I at $T_{t}=0.5$ and $1 \mathrm{~s}$ is $(86.71,81.89$ and 88.15) and (82.09, 62.91 and 85.02), respectively. For broad tank, the corresponding reduction is (78.71, 65.01 and 80.88) and (76.29, 75.28 and 76.22). Similarly, for slender tank, percentage reduction in tower drift for isolated model-II is $(87.48,83.65$ and 89.25$)$ and $(83.43$, 66.67 and 83.07), respectively, while for broad tank, the corresponding reduction is (80.72, 71.81 and 82.26) and (78.61, 77.42 and 76.32). These results indicate that the tower drift is reduced significantly due to isolation and this is more pronounced when tower structure is comparatively rigid. It is also observed that increased flexibility of tower structure transmits less earthquake forces but it increases the tower drift significantly. This implies that for stiff tower structure, the reduction in the
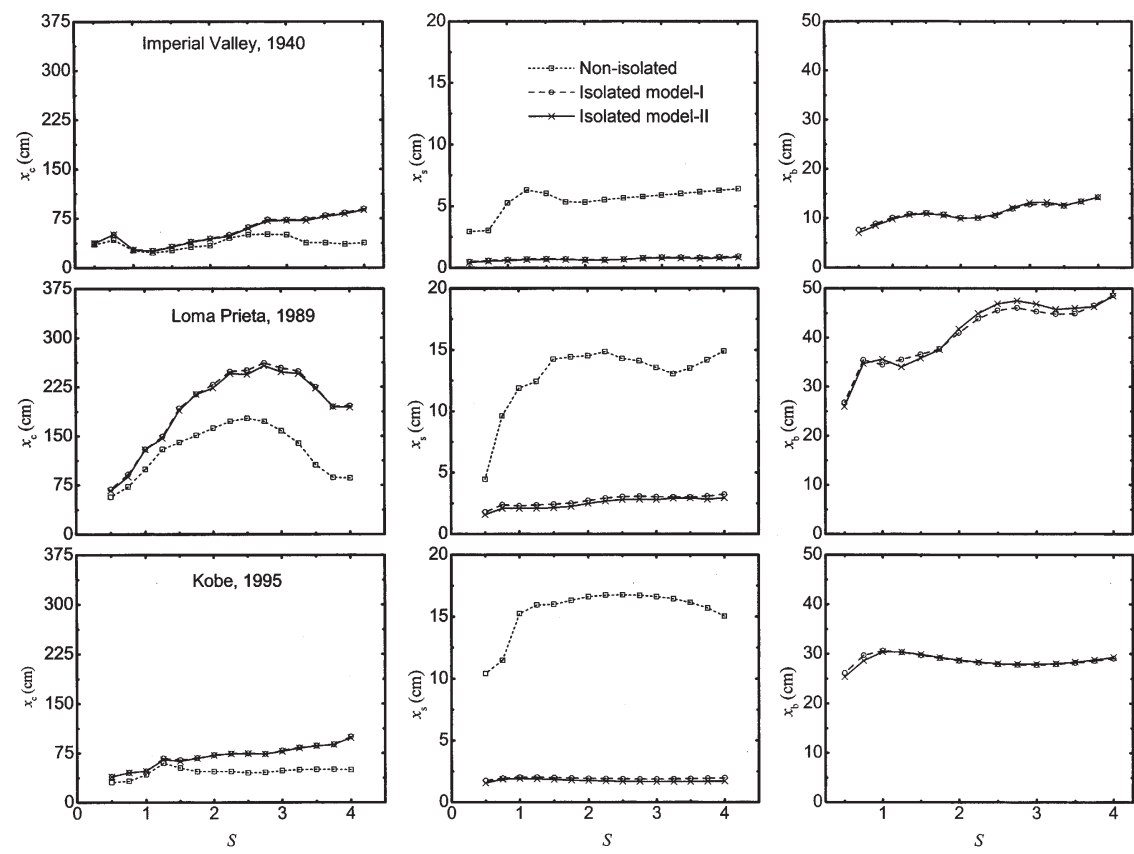

Fig. 5. Variation of peak sloshing displacement, tower drift and bearing displacement of elevated tank against aspect ratio $\left(T_{b}=2 \mathrm{~s}, \xi_{b}=0.1\right.$ and $\left.T_{t}=0.5 \mathrm{~s}\right)$. 

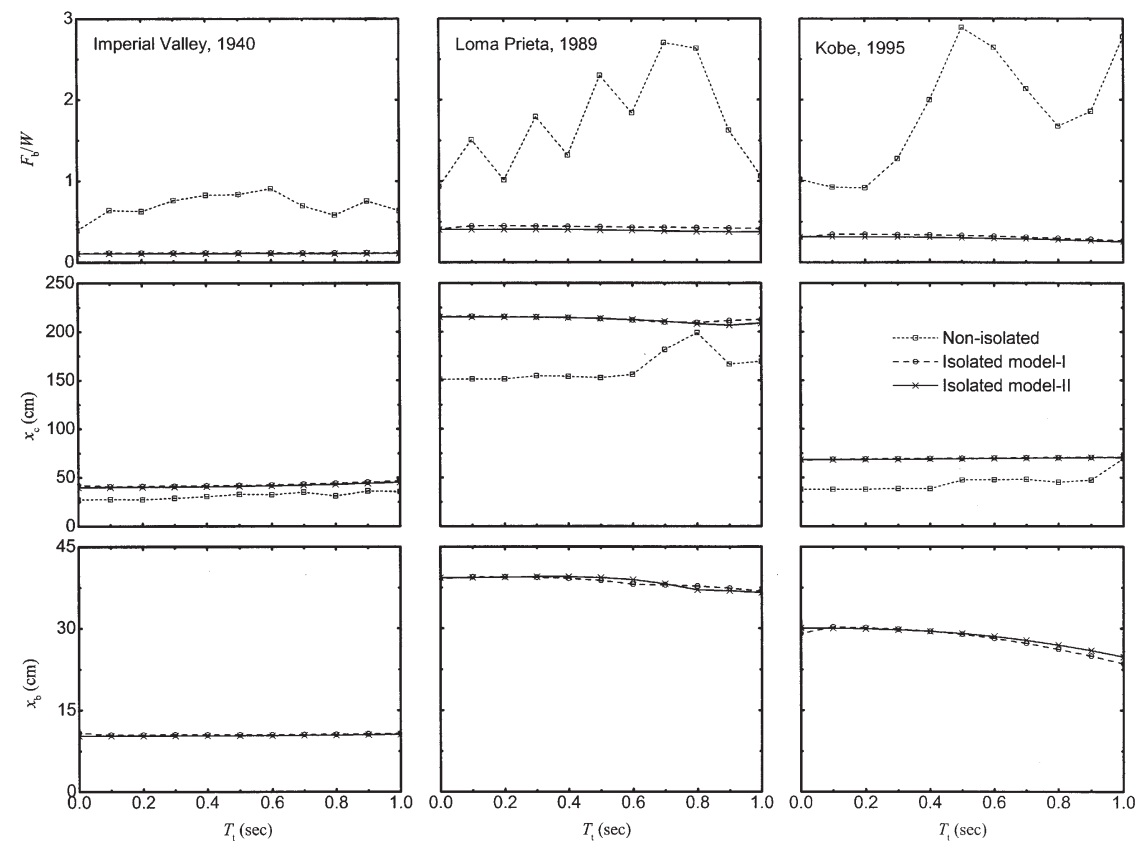

Fig. 6. Effects of time period of tower structure on the seismic response of slender tank $\left(T_{b}=2 \mathrm{~s}\right.$ and $\left.\xi_{b}=0.1\right)$.

response achieved is more in comparison to that of flexible tower structure. The peak sloshing displacement is increased significantly in slender tank, while in broad tank, it is not much influenced by the isolation effect. In addition, it is also found that the sloshing displacement in isolated slender tank marginally increases when flexibility of the tower structure increases.

\subsection{Effect of aspect ratio $(S)$}

In order to investigate the effectiveness of isolation, the response quantities of the tanks for wide practical range of elevated liquid storage tanks are plotted against aspect ratio, S. Fig. 4 shows variations of various components of base shear such as sloshing, impulsive, rigid and base under Imperial Valley, Loma Prieta and Kobe earthquakes for isolated and non-isolated conditions. It is observed that the contribution of sloshing component is slightly increased due to isolation but its overall contribution to total base shear is negligible, and hence does not influence the response. The equal contribution of rigid component and impulsive component to total base shear is slightly modified as a result of isolation. The variation shows that beyond the aspect ratio $S=1.5$, the rigid component contributes slightly more in comparison to that of impulsive component. It is also observed that the base component has negligible contribution. The variations of peak sloshing displacement, tower drift and bearing displacement against aspect ratio are illustrated in Fig. 5. The figure 
shows that initially, the increase in sloshing displacement of isolated tank is relatively less but gets amplified with the increase of the aspect ratio. This implies that in slender tank the increase of sloshing displacement is more in comparison to that of broad tank. But the tower displacement is significantly reduced due to isolation and the two isolated tank models (i.e. isolated models I and II) predict similar variation over the entire range of aspect ratio considered i.e. $S=0.5-4$. The bearing displacement initially increases as the aspect ratio increases up to 1.5 and beyond that there is no significant change in the displacement. Further, it is also observed that the two models of the isolated tanks predict identical bearing displacement.

\subsection{Effect of time period of tower structure $\left(T_{t}\right)$}

The effects of time period of tower structure, $T_{\mathrm{t}}$, on response of isolated tanks such as base shear, sloshing displacement and bearing displacement for slender tank are illustrated in Fig. 6 for different earthquakes. It has been found that the response of isolated tank is insensitive to the variation of $T_{\mathrm{t}}$ and the response predicted by the two tank models matches closely. The response of isolated tank is compared with corresponding response of the non-isolated tank and it is observed that base shear is significantly reduced over the entire range of the $T_{\mathrm{t}}$ considered. The sloshing displacement is increased in the isolated tank in comparison to non-isolated tank. Further, the two tank models predict similar bearing displacement. For the broad tank, a similar effect is observed as depicted in Fig. 7. Thus, it is concluded that
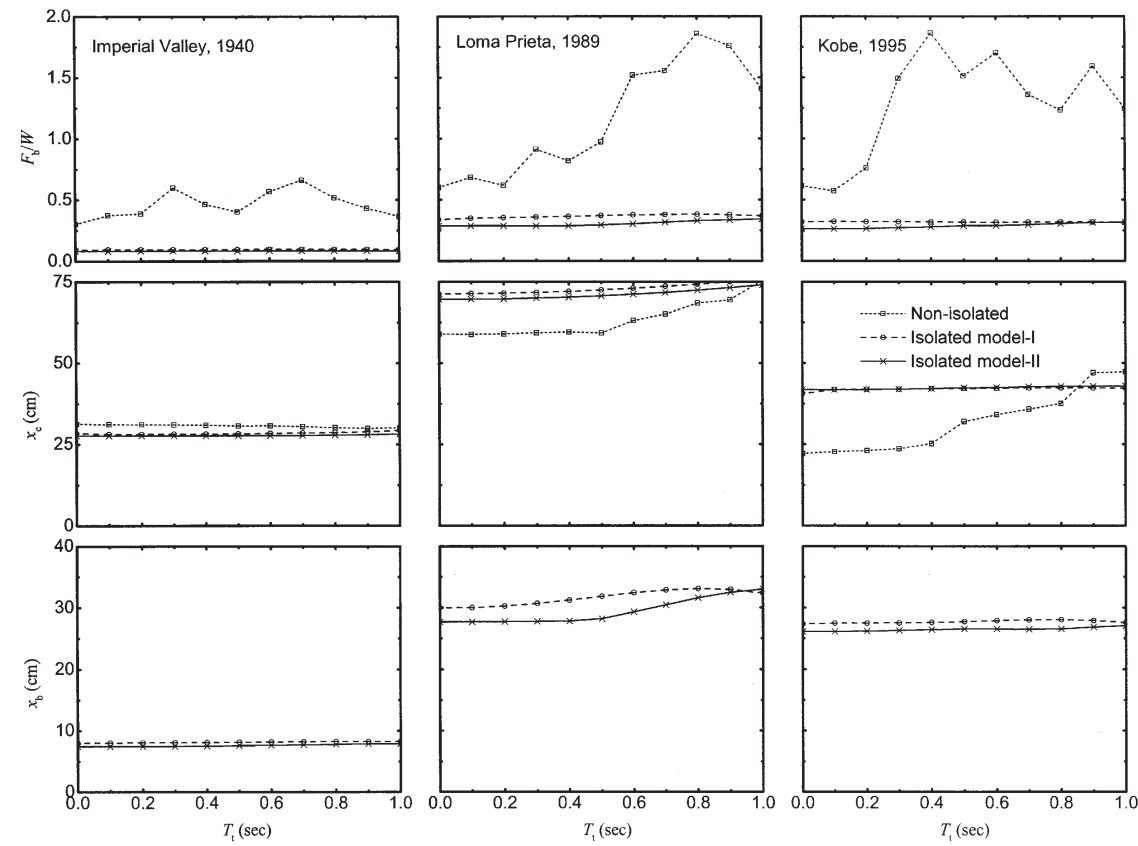

Fig. 7. Effects of time period of tower structure on the seismic response of broad tank $\left(T_{b}=2 \mathrm{~s}\right.$ and $\left.\xi_{b}=0.1\right)$. 
increasing the flexibility of the tower structure does not influence significantly the response of the isolated tanks.

\subsection{Effect of isolation damping $\left(\xi_{b}\right)$}

Fig. 8 illustrates the influence of isolation damping on the seismic response of slender tank predicted by the two isolated tank models. The figure indicates that base shear, sloshing displacement and bearing displacement reduce as the damping increases. It has been found that the reduction in the base shear and bearing displacement is significant up to $\xi_{b}=0.2$ and beyond that there is not much reduction in base shear and bearing displacement. The sloshing displacement gradually decreases as the isolation damping decreases. Fig. 9 depicts a similar behaviour of the broad tank and response obtained by the two tank models. This indicates that the appropriate selection of isolation damping is important to achieve the minimum response of the isolated tank.

\subsection{Effect of flexibility of isolation system $\left(T_{b}\right)$}

The influence of time period of isolation system on the peak response of slender tank is investigated as shown in Fig. 10. It is observed that the two tank models predict similar response, which closely matches implying the behaviour of the tower structure as a rigid body (i.e. tower drift is very small in the isolated tanks, refer
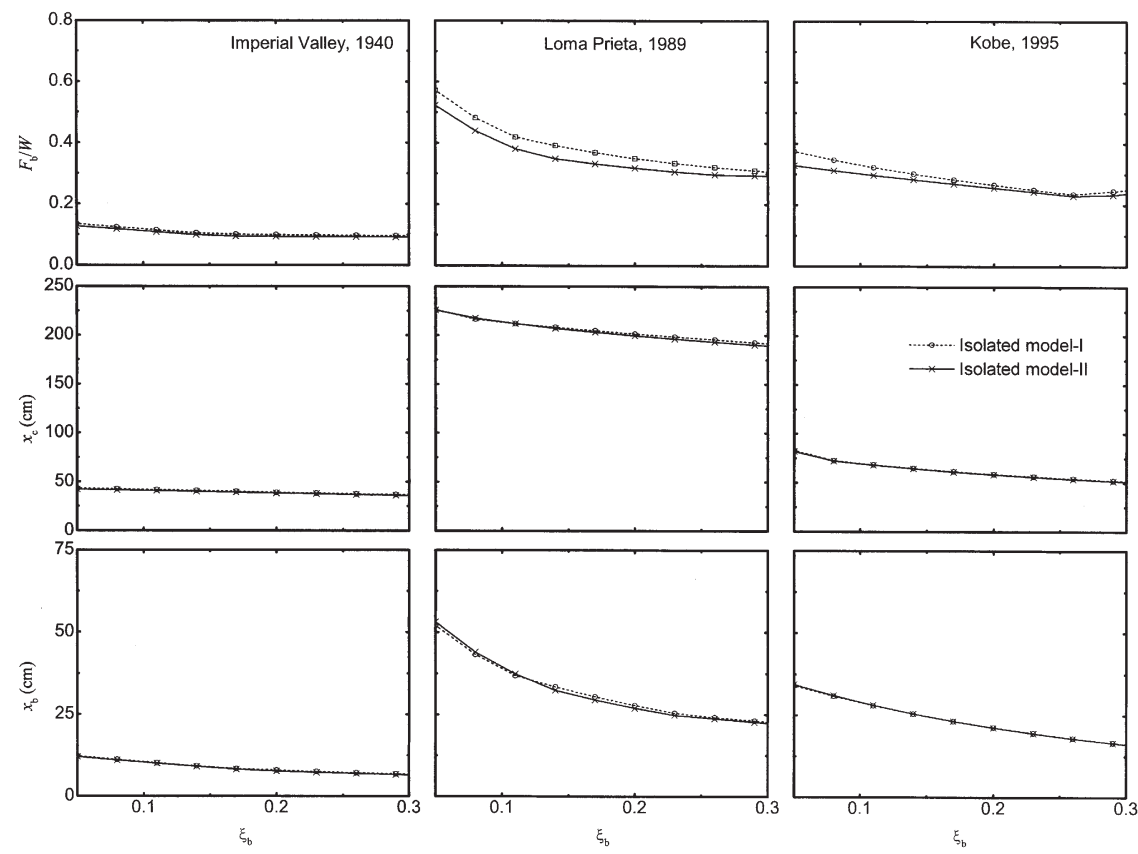

Fig. 8. Effects of isolation damping on the seismic response of slender $\operatorname{tank}\left(T_{b}=2 \mathrm{~s}\right.$ and $\left.T_{t}=0.5 \mathrm{~s}\right)$. 

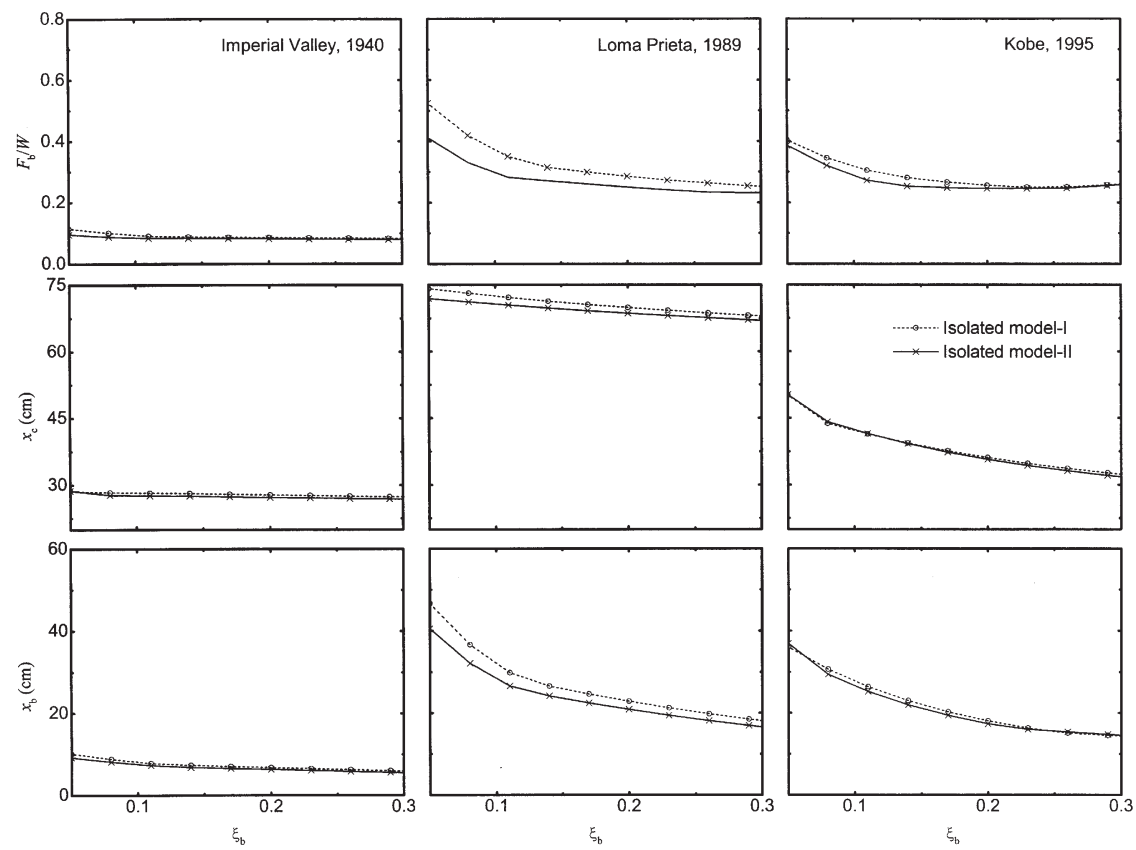

Fig. 9. Effects of isolation damping on the seismic response of broad tank $\left(T_{b}=2 \mathrm{~s}\right.$ and $\left.T_{t}=0.5 \mathrm{~s}\right)$.

Fig. 5). It is observed that due to increase of isolation period, base shear is reduced significantly because increased flexibility of the isolation system transmits less acceleration to liquid container, and hence less dynamic forces are generated. The sloshing displacement marginally increases with increase of time period and peaked in vicinity of $3 \mathrm{~s}$ which is close to period of sloshing mass (i.e. $3.66 \mathrm{~s}$ ) and further increase in period reduces the sloshing displacement. The bearing displacement increases as flexibility of the isolation system increases. A similar result is observed for broad tank as shown in Fig. 11 except sloshing displacement. The sloshing displacement is not significantly influenced by variation of the isolation period. This is due to the fact that the period of sloshing mass and range of isolation period considered are well separated.

\section{Approximate response analysis of isolated elevated tanks}

A previous study indicates that the impulsive displacement is very less in comparison to the other displacements, which further reduces due to isolation. It is also observed that due to isolation of the elevated tank, the deformation in the tower structure is very small. Therefore, it will be interesting to investigate the earthquake response of the isolated elevated liquid storage tank considering that impulsive mass rigidly moves with tank wall along with rigid mass and deformation of the tower structure is negligible (see Fig. 5). Hence, the reduced degree-of-freedom models of 

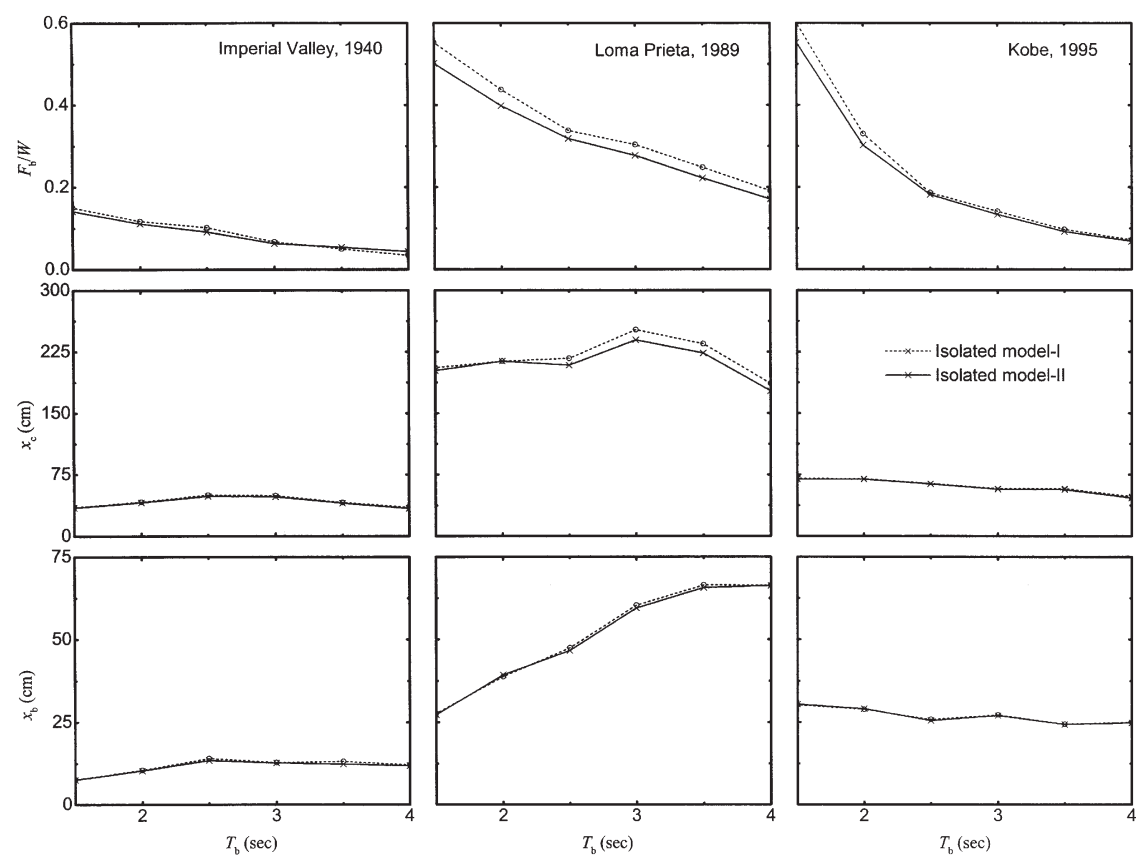

Fig. 10. Effects of isolation time period on the seismic response of slender tank $\left(\xi_{b}=0.1\right.$ and $T_{t}=$ $0.5 \mathrm{~s})$.

the isolated tanks (i.e. based on isolation models I and II) are shown in Fig. 12. Since the period of sloshing mass is quite high and well separated from the period of isolation system, it will be interesting to investigate the response of tanks by assuming that the sloshing mass moves independent of base motion. This assumption will generate two types of models, one in which motion of the sloshing mass is coupled with motion of base mass (i.e. is called coupled model), and another in which two masses have independent motion (i.e. decoupled model). The equations of the motion for the two tank models are solved numerically and response obtained by both decoupled and coupled analyses is compared.

The earthquake response of elevated liquid storage steel tanks is investigated using decoupled and coupled analyses with two-degrees-of-freedom system, which are associated with sloshing mass and bearing displacement. The two tank models considered for this analysis are based upon the reduced model of isolated models I and II. The reduced model of elevated liquid storage tank is used to investigate the response using decoupled and coupled analyses. The equivalent parameters such as stiffness and damping for sloshing mass, $\left(k_{\mathrm{c}}, c_{\mathrm{c}}\right)$ and the isolation system, $\left(k_{\mathrm{b}}, c_{\mathrm{b}}\right)$ are computed based on simple single-degree-of-freedom system. The mass $M_{\mathrm{b}}$ mentioned in Fig. 12 for model-I is equal to $m_{c}+m_{i}+3 m_{b}$, while for model-II, it is $m_{c}+m_{i}$. The mass $M_{0}$ lumped at the foundation level for model-I is equal to $2 m_{\mathrm{b}}$ and is null for model-II. For decoupled model analysis, the sloshing mass is subjected to improved acceleration (i.e. $\ddot{u}_{\mathrm{b}}=\ddot{x}_{\mathrm{b}}+\ddot{u}_{\mathrm{g}}$ ) for accurate estimation of the response. 

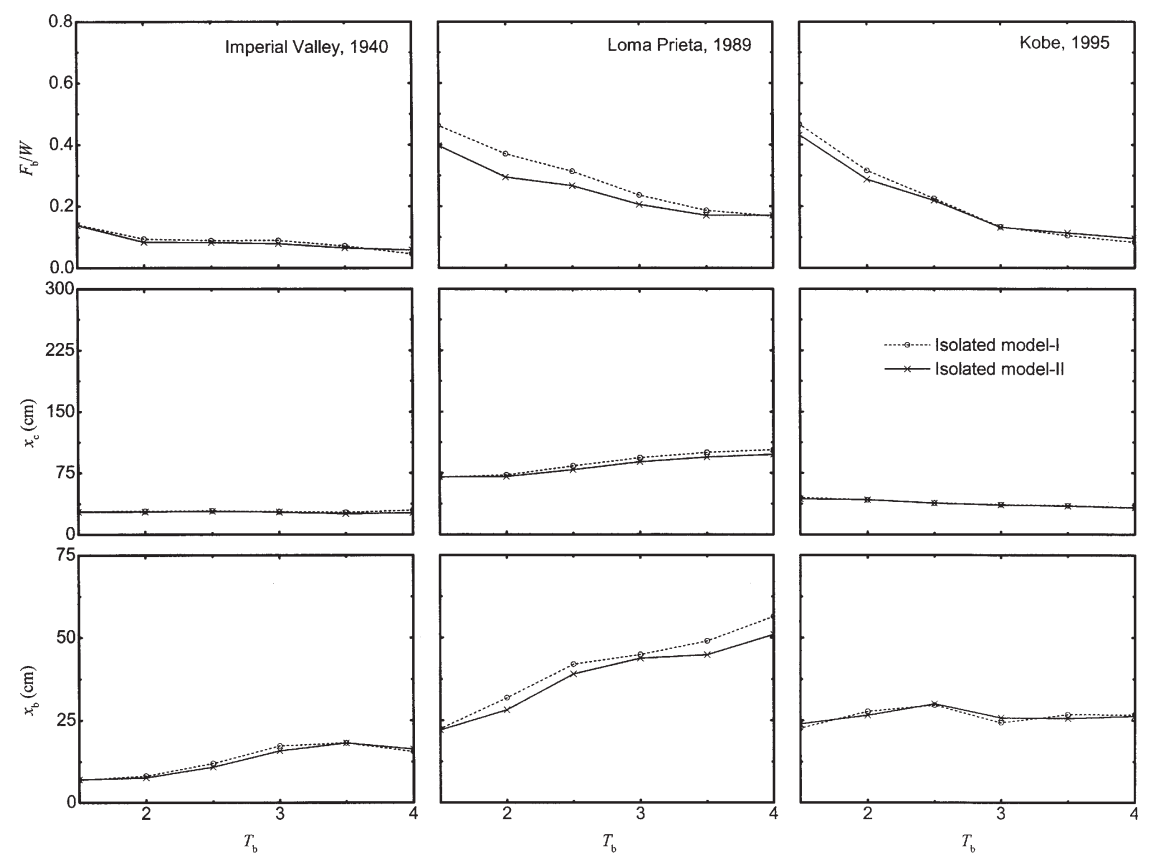

Fig. 11. Effects of isolation time period on the seismic response of broad tank $\left(\xi_{b}=0.1\right.$ and $T_{t}=0.5$ s).

(a)

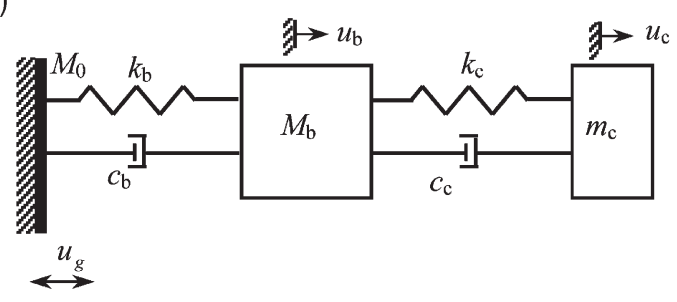

(b)
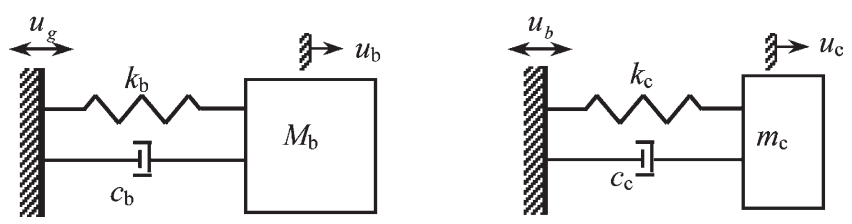

Fig. 12. Approximate model of isolated elevated liquid storage tanks (a) coupled model and (b) decoupled model. 
In order to verify the accuracy of the response obtained by decoupled analyses, the response is compared with the corresponding response predicted by coupled analysis and exact response (i.e. obtained by the four-degrees-of-freedom models, see Fig. $1(\mathrm{~b}),(\mathrm{c}))$.

Figs. 13 and 14 show the variation of peak response obtained by decoupled and coupled analyses for reduced isolated models I and II, respectively. It is observed that the coupled and exact analysis predicts the identical result and closely matches because period of the tower structure does not significantly influence response of isolated tanks (see Fig. 5). Further, the figures also indicate that the decoupled analysis predicts the conservative estimate of the response. This is because there is weak coupling between the sloshing frequency and isolation frequency specifically at lower aspect ratios, but at higher aspect ratios, there is strong coupling between the sloshing mass and isolation system. Therefore, the difference between the response predicted by the decoupled and coupled analyses is relatively more at higher aspect ratio in comparison lower aspect ratio. The bearing and sloshing displacements obtained by the decoupled analysis for both the models are slightly higher for broad tanks, while for slender tanks, the difference further increases. The base shear obtained by the decoupled analysis gives marginally higher result in comparison to coupled analysis and exact responses which are close, since the contribution of sloshing to total base shear is negligible. These results indicate that response of isolated elevated tanks can be predicted by decoupled analysis without losing the accuracy.
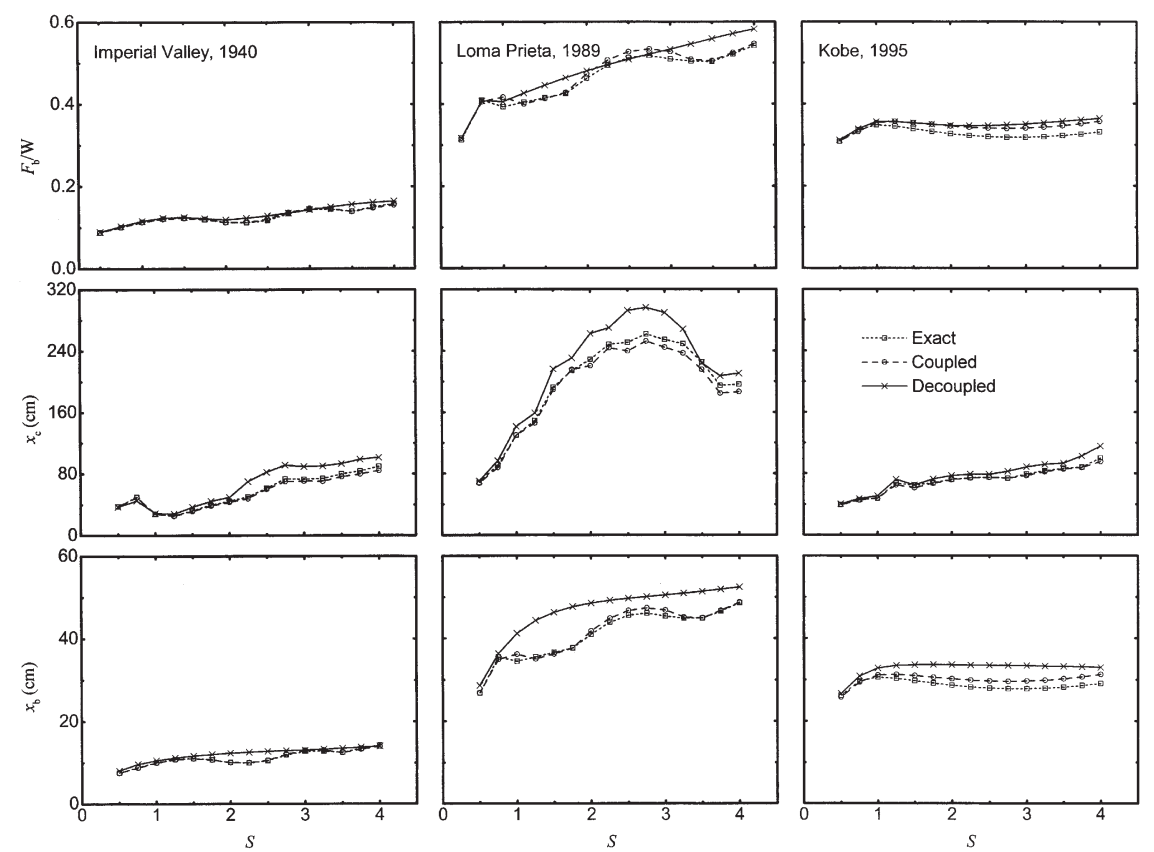

Fig. 13. Variation of approximate and exact response of the isolated tank model-I against the aspect ratio $\left(T_{b}=2 \mathrm{~s}\right.$ and $\left.\xi_{b}=0.1\right)$. 

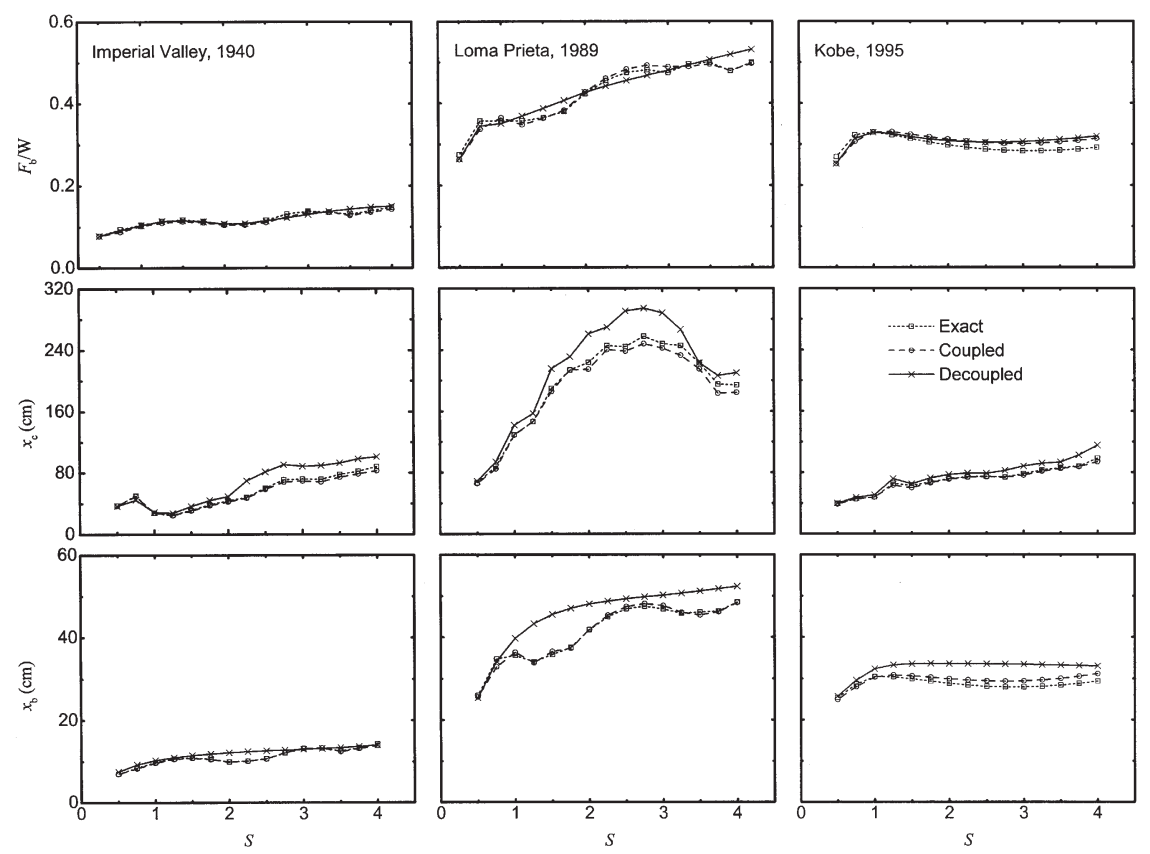

Fig. 14. Variation of approximate and exact response of the isolated tank model-II against the aspect ratio $\left(T_{b}=2 \mathrm{~s}\right.$ and $\left.\xi_{b}=0.1\right)$.

\section{Conclusions}

Comparative performance of elevated liquid storage tanks by putting the base isolation system at top and bottom of the supporting tower is investigated using real earthquake motions. The earthquake response of isolated tanks is compared with nonisolated tanks to measure the effectiveness of the isolation. In addition, a simplified decoupled analysis is proposed to investigate the response of isolated elevated liquid storage tanks. The following conclusions are drawn from the trends of the results of isolated elevated liquid storage tank:

1. It is observed that the base shear of elevated liquid storage tank is significantly reduced due to isolation. The base shear is mainly dominated by the impulsive and rigid mass components.

2. The drift of steel tower is also significantly reduced due to isolation. Further, the peak response of isolated tanks is insensitive to the period of the tower structure.

3. The peak earthquake response predicted by the isolated model-I is slightly more than the corresponding response obtained by the isolated model-II. However, in general, both the models provide the same effectiveness of base isolation.

4. The effectiveness of seismic isolation increases with the increase of bearing flexibility and damping. 
5. The peak sloshing displacement of slender tank is increased due to isolation effect while for broad tank it has no such influence.

6. The proposed approximate methods accurately predict the peak response of the isolated elevated steel tank with significantly less computational efforts.

\section{References}

[1] Steinbrugge KV, Rodrigo FA. The Chilean earthquakes of May 1960: a structural engineering viewpoint. Bull Seismol Soc Am 1963;53:225-307.

[2] Housner GW. Dynamic behavior of water tanks. Bull Seismol Soc Am 1963;53:381-7.

[3] Rosenblueth E, Newmark NM. Fundamentals of earthquake engineering. NJ: Prience-Hall, 1971.

[4] Haroun MA. Vibration studies and test of liquid storage tanks. Earthquake Eng Struct Dyn 1983;11:179-206.

[5] Hamdan FH. Seismic behaviour of cylindrical steel liquid storage tanks. J Constructional Steel Res 2000;53:307-33.

[6] Kelly JM. Aseismic base isolation: review and bibliography. Soil Dyn Earthquake Eng 1986;5:202-16.

[7] Buckle IG, Mayes RL. Seismic isolation history, application and performance-a world review. Earthquake Spectra 1990;6(2):161-202.

[8] Jangid RS, Datta TK. Seismic behaviour of base-isolated buildings: a-state-of-the-art review. J Struct Build, ICE 1995;110(2):186-203.

[9] Chalhoub MS, Kelly JM. Shake table test of cylindrical water tanks in base-isolated structures. J Eng Mech, ASCE 1990;116(7):1451-72.

[10] Kim NS, Lee DG. Pseudo-dynamic test for evaluation of seismic performance of base-isolated liquid storage tanks. Eng Struct 1995;17(3):198-208.

[11] Malhotra PK. Method for seismic base isolation of liquid storage tanks. J Struct Eng, ASCE 1997;123(1):113-6.

[12] Malhotra PK. New methods for seismic isolation of liquid-storage tanks. Earthquake Eng Struct Dyn 1997;26:839-47.

[13] Shrimali MK, Jangid RS. Seismic response of liquid storage tanks isolated by sliding bearings. Eng Struct 2002;24:907-19.

[14] Shrimali MK, Jangid RS. Non-linear seismic response of base-isolated liquid storage tanks to bidirectional excitation. Nucl Eng Des 2002;217:1-20.

[15] Bleiman D, Kim S. In: Proceeding, Seminar on Seismic Isolation, Passive Energy Dissipation and Active Control, ATC 17-1. Base isolation of high volume elevated water tanks. Redwood city, CA, USA: Applied Technology Council; 1993.

[16] Shenton III HW, Hampton FP. Seismic response of isolated elevated water tanks. J Struct Eng, ASCE 1999;125(9):965-76. 